\title{
TELUSUR KARYA RUAKH (ROH) DALAM PERJANJIAN LAMA
}

\author{
Gernaida KR. Pakpahan
}

\begin{abstract}
ABSTRAK
Pokok pembahasan terhadap pneumatologi memiliki cakupan wilayah yang sangat luas dan dalam untuk dikaji, baik yang terkait dengan sumber-sumber dari teks Kitab Suci maupun naskah-naskah non-biblikal. Fokus pemaparan dalam tulisan ini akan dikonsentrasikan kepada bagaimana gagasan umum tentang roh itu dipahami di dunia Timur Tengah Kuno. Selanjutnya bagaimana gagasan tentang roh itu berkembang dalam kehidupan umat Israel. Untuk memperoleh pemahaman yang komprehensif maka telusur terhadap dinamika karya Roh akan dilakukan melalui penyelidikan terhadap uraian yang tersaji dalam kitab Taurat, Sejarah, Syair dan Nabi-nabi.
\end{abstract}

Kata Kunci: Roh Allah, Roh, ruakh

\section{PENDAHULUAN}

Percakapan di seputar pneumatologi lebih menonjol dalam Perjanjian Baru (PB) jika dibandingkan dengan Perjanjian Lama (PL). Hal itu terkait dengan teks-teks PL yang memuat tentang "roh" jauh lebih sedikit dibanding teks-teks PB. Dominasi karya Roh Kudus dalam PB merupakan sumber utama dalam berbagai kajian teologis.

Apalagi setelah Pentakosta, umat berkeyakinan bahwa Roh Kudus berkarya lebih dinamis dan dalam dimensi yang lebih luas lagi. Sebagai perayaan yang mengakar kuat dalam tradisi masyarakat Yahudi, seperti halnya dalam perayaan Pentakosta di Yerusalem (Kis. 2:1-13); umat Allah memperoleh sukacita yang besar. Peristiwa "Pencurahan Roh Kudus" itu dipandang sebagai kegenapan dari nubuat nabi Yoel (Y1. 2:28-29).

Nabi Yoel bernubuat bahwa akan ada suatu hari dimana Roh Allah akan dicurahkan, bukan hanya kepada para imam dan nabi, melainkan juga kepada orangorang awam, tanpa memandang laki-laki atau perempuan, tingkat usia atau golongan. ${ }^{1} \quad$ Fakta ini memperlihatkan bahwa PL sendiri juga memuat informasi penting tentang karya Roh Allah. Meski para penulis PL tidak memberi informasi seintensif para penulis PB tentang roh Allah

1 Pedoman Lengkap Pendalaman Alkitab The Lion Handbook to the Bible, terj. Yap Wey Fong, dkk (Bandung: Kalam Hidup, 1983), 495 itu namun bukan berarti perhatian kita kurang penting terhadap PL. Untuk itu, perlu kesadaran tinggi dalam menggali dan mengeksplorasi dokumen-dokumen yang dimiliki PL tentang "roh" itu. Namun agar fokus pembahasan lebih terarah maka penjabaran berikut ini akan dikonsentrasikan kepada beberapa pertanyaan seperti berikut ini:

1. Bagaimana gambaran umum tentang "roh"?

2. Bagaimana pandangan Timur Tengah Kuno terhadap "roh"?

3. Bagaimana roh dan Roh Allah berkarya dalam Perjanjian Lama?

\section{Gambaran Umum Tentang Roh}

Penjelasan berikut ini memberi gambaran umum terhadap pengertian tentang roh dan bagaimana ide itu berkembang menjadi ungkapan yang umum dipakai di Timur Tengah Kuno.

\section{Definisi ruakh}

Istilah ruakh (kata רוּ Ibrani) umumnya memiliki beberapa pengertian yang cukup menonjol antara lain: "angin, nafas, pikiran atau roh." Adapun pengertian yang termuat di dalamnya hendak menunjuk kepada "sebuah kuasa yang memberi kehidupan." Di dunia Timur Tengah Kuno, karakteristik dari "roh" atau 
"angin" itu sesuatu yang berhembus ke mana dihendakinya.

Sekalipun kita tidak dapat melihatnya dengan mata tetapi dapat dirasakan kehadirannya. Mengenai asal usul gagasan tentang "roh" harus diakui, ada kesulitan tersendiri bagi para ahli untuk memahami konsep itu dan bagaimana pengembangannya di kemudian hari. Secara khusus di Israel, yang dapat dilakukan adalah menelusurinya informasi yang tersaji dalam Perjanjian Lama.

Menyelidiki penggunaan kata "roh" dalam PL maka ada baiknya dikaji bagaimana ungkapan itu dikenakan para penulis kitab-kitab PL. ${ }^{2}$ Secara leksikal, kata "ruakh" digunakan sebanyak 389 kali dalam berbagai bentuk maupun peristiwa. Sementara dilihat dari penggunaan bahasa maka pemakaian kata ruakh yang menunjuk kepada "roh" muncul sebanyak 378 kali dalam bahasa Ibrani, dan 11 kali dalam bahasa Aram (ini khusus dalam kitab Daniel). Dari jumlah itu sekitar 107 kali merujuk kepada kegiatan dan aktifitas Allah di alam semesta termasuk dalam kehidupan manusia. $^{3}$

Bagaimana kitab-kitab PL menggunakan kata "ruakh" maka informasi yang diperoleh sebagai berikut:

1) Pentateukh.

Ungkapan tentang "roh" dalam kitab Musa dijumpai berbagai dimensi dan gambaran yang cukup beragam. Intensitas pemakaian kata itu sebanyak 38 kali, sekalipun ungkapan itu tidak didapati dalam kitab Imamat. ${ }^{4}$

2) Kitab Sejarah.

Sementara informasi yang diperoleh dari kitab nabi-nabi terdahulu, penggunaan kata ruakh "roh" dipakai sebanyak 47 kali. Pengertiaan kata itu juga aneka ragam, sesuai dengan konteks di mana kata itu dipakai.

${ }^{2}$ Bible Works, 9. רוּ ruakh TWOT - wind, breath, mind, spirit Spirit or spirit 232, wind 92, breath 27 , side 6 , mind 5 , blast 4 , vain 2 , air 1 , anger 1 , cool 1 , courage 1 , misc $6 ; 378$

3 J.D.G. Dunn, "Spirit, Holy Spirit", The Illustrated Bible Dictionary, Part 3, P-Z, Ed. Mary
3) Kitab nabi-nabi.

Penggunaan kata ruakh "roh" pada kitab nabi-nabi yang terkemudian jauh lebih dominan. Hal itu terlihat dari seringnya kata itu digunakan yaitu sebanyak 154 kali. $^{5}$ Di sini terlihat bahwa dalam literatur nabi-nabi pembuangan dan pasca pembuangan pemakaian kata "roh" itu jauh lebih mendominasi kitab lainnya.

4) Kitab Syair.

Dalam sastra hikmat atau syair, penggunaan kata "roh" juga tidak kalah penting. Kata "roh" dipakai sebanyak 139 kali, termasuk dengan penambahan 11 kali dalam kitab Daniel yang menggunakan bahasa Aram. ${ }^{6}$

Telaah lebih mendalam terhadap apa sesungguhnya makna kata ruakh "roh," akan dipaparkan sebagai berikut:

Pertama, ruakh istilah umum yang digunakan untuk merujuk kepada "angin" atau "udara yang bergerak". Jika kata ruakh digunakan dalam pengertiannya sebagai "angin" maka akan dikaitkan dengan kuasa yang tidak kelihatan, sebuah misteri, atau kuasa yang dashyat (Kej. 8:1; Kel. 10:13, Bil. 11:31; 1 Raj. 18:45, dll).

Kedua, ruakh bisa diartikan sebagai suatu yang menunjuk kepada "nafas." Sebagaimana lazimnya kata ruakh diartikan sebagai "nafas atau roh." Keadaan seperti ini merupakan identitas mahluk hidup, juga termasuk di dalamnya manusia maupun hewan (Kej. 6:17; 7:15; Mzm. 31:5; 32:2; Pkh. 3:19, 21; Yer. 10:14; Yeh. 11:5); atau "kuasa misterius" (Kej. 41:8; Hak. 8:3; 1 Raj. 21:5; 1 Taw. 5:26; Ayb. 21:4).

Ketiga, ruakh "roh" dalam pengertian antropologis. Penggunaan kata "roh" pada konsep antropologis sebagai referensi yang memperlihatkan emosi atau keberadaan manusia. Manusia adalah mahluk yang memiliki perasaan, hati, batin

Gladstone, etc. (Leicester: Inter-Varsity Press, 1980), 1478-1483.

${ }^{4}$ J.D.G. Dunn, "Spirit, Holy Spirit”, 1478

5 J.D.G. Dunn, "Spirit, Holy Spirit", 1479

6 J.D.G. Dunn, "Spirit, Holy Spirit”, 1480. 
yang tampak dalam berbagai situasi dan kondisinya. Masih terkait dengan antropologi, kata "roh" digunakan untuk mengekspresikan prinsip hidup yang menjiwai manusia.

Keempat, ruakh merujuk kepada kemahakuasaan Tuhan. Tidak dapat dipungkiri bahwa penggunaan kata ruakh itu juga untuk menunjuk pada kemahakuasaan TUHAN. Ada kalanya penggunaan frasa ruakh adonay "roh TUHAN" atau ruakh elohim "roh ALLAH" itu tumpang tindih, namun yang harus dipahami adalah bahwa tidak ada per-bedaan makna diantara keduanya. TUHAN yang memilih dan melengkapi para hambaNya agar mereka memiliki otoritas dan kemampuan melakukan tugas yang diembannya. Kehadiran ruakh itu nyata dalam hal Tuhan membebaskan umatNya (Hak. 3:10; 6:34). Dengan kuasa roh TUHAN maka para nabi dilengkapi sehingga memiliki keberanian untuk menyampaikan pesanNya (1 Sam. $10: 6 ; 10 ; 19: 20,23){ }^{7}$

Untuk menjelaskan sesuatu yang abstrak seringkali digunakan simbol atau ungkapan, termasuk di dalamnya penggunaan kata "roh". ${ }^{8}$ Ada kalanya frasa "roh" dalam PL dipakai secara simbolik untuk menunjuk kepada "tangan Tuhan." Simbol lain juga terlihat dalam bentuk air, minyak urapan, berkat atau berbagai ekspresi lainnya. Bahkan karya roh Allah juga dinyatakan dengan ekstase (kesurupan atau kepenuhan roh), roh yang membawa kedamaian atau pemulihan, roh yang dikaitkan dengan pekerjaan yang perkasa. Aneka konsep tentang "roh" dalam PL akan menjadi dasar untuk memahami "roh" dalam Perjanjian Baru.

\section{Asal Usul Istilah ruakh "Roh"}

Secara historis perkembangan pemakaian kata "roh" sangat beraneka ragam. Dalam Alkitab sendiri, kata "roh"

\footnotetext{
${ }^{7}$ J.D.G. Dunn, "Spirit, Holy Spirit", 1481.

${ }^{8}$ Perlu dicatat bahwa ada beberapa kitab dalam PL sama sekali tidak menggunakan roh Allah seperti Obaja, Esther, Kidung Agung, Rut.
}

pertama kali dipakai dalam Kej. 1:2. Ayat ini menjadi bukti permulaan bagaimana penggunaan kata itu dalam PL. Penyebutan "roh Allah" melayang-layang di atas permukaan air menunjukkan konsep hubungan yang terjalin antara Allah dengan alam semesta, khususnya antara manusia dengan Allah.

Untuk memahami ayat ini maka perlu dikaji latar belakang konteksnya agar terlihat dari mana PL mengadopsinya. Perspektif bahwa roh itu menghidupkan rupanya sudah umum diterima di antara bangsa-bangsa Timur Dekat Kuno, daerah dimana Israel hidup berdampingan dengan bangsa-bangsa itu. ${ }^{9}$ Dalam kenyataanya PL juga memahami bahwa "roh" adalah kuasa yang menghidupkan.

Pijakan yang mendasari keyakinan bangsa-bangsa, tetangga Israel itu terhadap eksistensinya sebagai manusia tidak dapat dilepaskan dari keberadaan dewa-dewi. Maka pemahaman yang terkait dengan adanya "roh" bukanlah sebuah konsep yang sulit dipahami dalam relasi mereka dengan kuasa yang menghidupkan. Artinya, "roh" dipandang sebagai kuasa yang menghidupkan dan menggerakkan manusia dalam melakukan aktivitasnya. Mereka memahami "roh" adalah bagian dari dewa dan dewi yang terlibat aktif dalam kehidupannya, kuasa yang meng-gerakkan dan memberi kesuburan bagi tanaman dan binatang agar hidup manusia dapat terpelihara.

Dengan demikian mudah dipahami bahwa Israel kemungkinan besar mengadopsi istilah itu dengan maksud yang khusus sesuai dengan keyakinan mereka terhadap TUHAN. Pengambilalihan konsep itu dari negara tetangga Israel sedikit banyak juga akan mempengaruhi mereka dalam membentuk pemahamannya tentang "roh" dalam relasinya dengan TUHAN. Jadi, kata itu harus dilihat dalam teropong

9 Hildebrandt, Wilf, An Old Testament Theology of the Spirit of God (Peabody, Massachusetts: Hendrickson Publisher, 1995), 4 
PL yang memiliki konteks dan latar belakang pneumatologi-nya sendiri dan bukan dari sudut pandang PB.

\section{Kehidupan Di Timur Dekat Kuno}

Berbagai kemiripan pandangan yang dimiliki Israel ternyata sama dengan bangsa-bangsa Timur Tengah Kuno, baik yang menyangkut alam semesta, ketuhanan, roh dan kehidupan lain. ${ }^{10}$ Seorang ahli yang bernama J. Hehn memberikan bukti bahwa dalam budaya Mesir diyakini bahwa para dewa, terutama Amon, juga memberi "nafas hidup" kepada mahluk. Bagi orang Mesir, nafas kehidupan atau lebenatem dianggap sebagai "kuasa yang menghidupkan". Oleh karena itu, nafas kehidupan itu juga dikaitkan dengan nafas Amon dan Horus. ${ }^{11}$ Pandangan seperti itu dijumpai dalam beberapa teks PL antara lain, "ketika itulah TUHAN Allah membentuk manusia itu dari debu tanah dan menghembuskan nafas hidup ke dalam hidungnya; demikianlah manusia itu menjadi makhluk yang hidup" (Kej 2: 7; bnd. Ayub 33: 4). ${ }^{12}$

Orang Mesir percaya, khususnya para raja menerima nafas hidup dari para dewa. Para raja sangat istimewa dalam kedekatannya dengan dewa-dewi itu. Sekalipun ada relasi yang sangat dekat antara raja dengan para dewa, namun tidak ada teks atau dokumen dalam sastra Mesir yang memperlihatkan bahwa atribut nafas hidup itu sebagai "roh para dewa." Maka perlu diperhatikan bahwa ada ekspresi yang berbeda mengenai "roh" manusia juga untuk membedakannya dengan pengertian angin, semangat, dan ke-hidupan, dll. ${ }^{13}$

Jadi pemahaman Mesir terhadap "roh" itu sangat tergantung dengan aspek budaya dan konteks yang melatarbelakanginya, yaitu relasi manusia dengan

${ }^{10}$ Wilf, An Old Testament Theology of the Spirit of God, 4

${ }^{11}$ Hehn, "Problem' 216-18

12 H. Kleinknecht, "pneuma, pneumatics' TDNT, 6.339-42

${ }^{13}$ Hehn, "Problem' 216-18 para dewa. Meskipun sekilas ada kaitannya dengan bagaimana PL memahami "roh", namun tampaknya pandangan PL memiliki perbedaan yang sangat signifikan. Sebab dalam literatur PL, konsep nafas hidup sangat terkait dengan pemberi "roh" yaitu Allah sendiri.

\section{"Angin, Air, dan Nafas" di Timur Dekat Kuno}

Dalam literatur Semit Barat, khususnya di Ugarit, kata $r h$ memiliki pengertian yang setara dengan istilah ruakh dalam PL. Aneka ragam pendapat yang dijumpai di Timur Dekat Kuno untuk menjelaskan kata $r h$, diterjemahkan antara lain "angin, nafas, aroma." Dalam bahasa Aram kata "roh" dimaknai sebagai "angin, semangat." Hampir senada dalam bahasa Arab yaitu "nafas hidup," "roh" atau "angin."

Namun ada kalanya kata $r h$ memperlihatkan fenomena alam seperti petir, hujan, dan badai. Bahkan Baal disebut sebagai "pengendara dari awan". ${ }^{14}$ Ungkapan yang sama juga didapati dalam PL pemazmur mengungkapkan, "Ia mengendarai kerub, lalu terbang dan melayang di atas sayap angin" (bnd. Mzm 18:10). Di sini terlihat jelas bahwa penggunaan kata ruakh itu lebih menonjol kepada "angin, unsur nafas, udara, atau atmosfer". ${ }^{15}$

Dalam sastra Timur Dekat Kuno, kata ruakh jarang sekali digunakan untuk menunjuk kepada roh Allah. Namun dalam penggunaan kata ruakh sebagai instrumen yang digunakan para dewa untuk menyatakan maksudnya cukup sering. Hal itu terlihat dalam naskah-naskah Mesir, mitos penciptaan tidak hanya sekedar berbicara tentang dewa yang memberi "nafas hidup" pada manusia.

\footnotetext{
${ }^{14}$ Wilf, An Old Testament Theology of the Spirit of God, 4-5

${ }^{15}$ Akar $r$ terjadi pada semua bahasa Semit kecuali untuk cabang timur. A. R. Johnson, The Vitality of the Individual in the Thought of Ancient Israel (2d ed.; Cardiff: University of Wales Press, 1964) 23.
} 
Dalam narasi Babilon, Marduk juga tidak mengacu pada aspek jiwa manusia. Malahan sebaliknya, Marduk mendapat pujian karena ia memberikan "nafas hidup" kepada dewa-dewa. Marduk diyakini sebagai dewa yang mengendali-kan atmosfir, termasuk mengendalikan sakit penyakit yang menimpa manusia. ${ }^{16}$ Yang hendak diperlihatkan dalam mitologi Timur Tengah Kuno adalah peranan "roh" sangat tergantung pada masing-masing dewa.

\section{Kronologi Penggunaan kata "Roh"}

Para ahli mengalami kesulitan untuk menetapkan kapan sesungguhnya penggunaan istilah "roh" mulai dikenakan sehingga konsep itu digunakan dalam PL. Ada beberapa pandangan yang berbeda berusaha menjelaskan kapan penggunaan kata itu. ${ }^{17}$ Misalnya W R. Schoemaker secara subjektif menduga bahwa penggunaan istilah "roh" itu popular sekitar 900700 sM, dimana ruakh dipahami sebagai "roh" dan "angin". ${ }^{18}$

Ia mengganggap bahwa penggunaan ruakh sebagai "udara dalam gerakan" dalam pandangan Ibrani merupakan pemikiran yang kurang tepat. Menurutnya kata "roh" itu lebih tepat diartikan sebagai "energi" atau "kuasa yang tidak dapat dilihat." Schoemaker lebih lanjut melihat hubungan antara angin dan semangat seperti yang dicatat dalam Alkitab jelas terkait dengan Allah yang memperlihatkan kuasaNya berkarya dalam diri manusia. ${ }^{19}$

Menurut Schoemaker, kata ruakh juga berkenaan dengan berbagai pengertian, diantaranya menunjuk kepada kekuatan fisik yang dimiliki seseorang, keberanian, dan kemarahan, yang menunjukkan hubungan antara Allah dan aktivitas di dalam diri manusia. ${ }^{20}$ Baginya, hubungan

$726-27$

${ }^{16}$ Albertz dan Westermann, "ruah, Geist,"

\footnotetext{
${ }^{17}$ Wilf, An Old Testament Theology of the Spirit of God, 5-6

${ }^{18}$ WR. Schoemaker, "The Use of ruah in the Old Testament and of pneuma in the New Testament," JBL 23 (1904) 13.
}

antara "angin" dan "roh" juga dijumpai dalam korespondensi antara kuasa yang tidak terlihat. Jadi pemahaman yang mengaitkan ruakh dengan "nafas" adalah ungkapan yang sudah umum digunakan sebelum masa pembuangan.

Namun masalah utama dengan pendapat seperti ini adalah penggunaan teks dan dokumen PL yang terlalu subjektif. Misalnya, pemaksaan terhadap dokumen sebelum pembuangan akan gagal untuk mengenali asal muasal beberapa ayat Alkitab seperti Keluaran 15: 8 "Karena nafas hidung-Mu segala air naik bertimbun-timbun; segala aliran berdiri tegak seperti bendungan; air bah membeku di tengah-tengah laut". Juga ada kesulitan untuk memahami teks 2 Samuel 22:16, "Lalu kelihatanlah dasar-dasar laut, alasalas dunia tersingkap karena hardikan TUHAN karena hembusan nafas dari hidung-Nya". Selanjutnya F. M. Palang memberikan bukti akan adanya asal muasal untuk perikop ini. Jadi ruakh dipakai baik untuk "angin" maupun "nafas" adalah dalam pengertian angin atau udara yang bergerak, yang memperlihatkan dunia manusia yang luas yang dipengaruhi aspek fisik "bernafas" maupun antropologis "perasaan". 21

\section{Pneuma dalam Septuaginta dan Sastra Yunani}

Sastra Yunani memberikan informasi penting tentang pneuma, meskipun tidak secara langsung berhubungan dengan latar belakang pengembangan kata ruakh dalam PL, maupun yang terkait dengan pemakaiannya dalam terjemahan di LXX. Secara sederhana kata dasar pneuma, berarti "meniup" atau "bernafas." Ternyata

19 WR. Schoemaker, "The Use of ruah in the Old Testament...", 14

${ }^{20}$ Schoemaker, "The Use of ruah in the Old Testament," 19

${ }^{21}$ Tengstrom, "ruah," 390-93. 
kata sama juga dipakai untuk pengertian "angin" atau "udara". 22

Dalam LXX kata ruakh diterjemahkan dengan anemos bukan pneuma sebagaimana digunakan dalam pengertian "angin," dan kata ini digunakan sebanyak 52 kali. Sementara penggunaan kata ruakh sebagai pneuma dipakai sebanyak 277 kali. Tampaknya kata pneuma tidak hanya mengacu pada pengertian "angin" dan "nafas kehidupan" dalam LXX, juga menunjuk kepada kekuasaan manusia super (supranatural), kemampuan spiritual, keinginan, kehendak, jiwa, pengharapan eskatologis bahkan prinsip hidup manusia. $^{23}$

Dalam literatur Yunani klasik istilah pneuma diklasifikasikan menjadi dua bagian penting. Pertama, sebagian besar pemakaian kata pneuma adalah dalam pengertian "angin", yang menunjuk kepada "angin lembut untuk meredakan kekerasan". Kedua, kata pneuma digunakan dalam pengertian "napas yang keluar bagi pernafasan, atau yang menunjukkan nafas kehidupan".

Cara mudah untuk mengenali faktor eksternal bagi mahluk hidup adalah pernafasan. Selama binatang atau manusia bernafas maka dengan mudah mengidentifikasinya sebagai mahluk yang hidup. Sebaliknya jika tidak ada tanda-tanda pernafasan yang konsisten maka dapat dikategorikan kehidupan dianggap tidak ada atau mati. Dalam pengertian demikian terlihat dengan jelas bahwa nafas menjadi simbol kehidupan dan berhubung-an dengan udara yang bergerak. Jadi tandatanda yang jelas terlihat, masih mempengaruhi materi fisik dengan cara yang tampak terlihat. ${ }^{24}$

Oleh karena itu, pengertian ruakh sebagai 'angin' yang menunjukkan adanya

${ }^{22}$ H. G. Liddell and R. Scott, "pneuma," A Greek-English Lexicon, reprinted ed., Revised by H. S. Jones (Oxford: Clarendon, 1978) 1424.

23 W Bieder, "pneuma, pneumatikos," TDNT, 6.368-7

${ }^{24}$ Wilf, An Old Testament Theology of the Spirit of God, 7-8 udara yang bergerak baik yang menunjuk kepada hakikat natur manusia, yang ada di dalam dirinya, yaitu nafasnya sendiri maupun binatang." ${ }^{25}$ Selanjutnya pengertian pneuma sebagai "angin dan nafas kehidupan" dalam sastra Yunani istilah itu terkait dengan "jiwa, mental, spiritual, inspirasi, sesuatu yang ilahi, dan sebagai kuasa kosmis dan alam semesta". ${ }^{26}$ Menurut Kleinknecht dan W Porzig, kata benda pneuma berarti "elemen penting dalam kekuatan alam, proses terjadinya sesuatu, adanya aliran udara pada hembusan angin, menghirup dan menghembuskan nafas, adanya nafas yang menghidupkan, cara untuk mendeteksi perkara lahir dan batin, adanya inspirasi, bahkan semangat atau antusiasme. ${ }^{27}$

Penggunaan asosiasi kata ruakh dengan nafas atau pernafasan menunjukkan adanya tanda-tanda kehidupan, adanya potensi semangat yang menghidupkan sekalipun tak terlihat oleh mata. Adanya faktor eksternal yang dapat mempengaruhi semangat bagi seseorang sehingga pada akhirnya akan menyebabkan perubahan dalam "roh" manusia yang mempengaruhi watak dan emosinya. ${ }^{28}$ Kata "roh" adalah ungkapan yang ideal untuk menunjukkan kemahakuasaan Allah dalam mempengaruhi alam semesta termasuk di dalamnya manusia.

Di alam semesta, Allah dapat mengutus angin yang tak terlihat mempengaruhi segala sesuatu baik secara positif maupun dalam hal negatif seperti angin yang membawa bencana dan gangguan atmosfer. Sehubungan dengan keberadaan manusia, Allah sendirilah yang bertindak memberikan nafas kehidupan baginya sehingga manusia dimampukan hidup dengan pernafasannya, bertindak dalam aktivitasnya termasuk mengelola watak dan

25 W Eichrodt, Theology of The Old Testament (trans J. A. Baker; Philadelphia:. Westminster, 1967) 2,46.

${ }^{26}$ Kleinknecht, "pneuma," 336-39

${ }^{27}$ Kleinknecht, "pneuma," 334-35

${ }^{28}$ Wilf, An Old Testament Theology of the Spirit of God, 9 
karakternya. Dengan "roh" itu, Israel memahami bagaimana cara terbaik untuk berkomunikasi dengan Allah, untuk merasakan kehadiranNya meskipun tak terlihat dan untuk bersekutu denganNya. Oleh sebab itu ruakh meskipun tak terlihat namun Allah memperlihatkan tindakan dan karyaNya yang nyata dalam dunia dan dalam sejarah manusia.

\section{Ruakh sebagai "angin" dalam Taurat, Para Nabi, dan Kitab-kitab Ruakh dalam kitab-kitab Taurat (Tora).}

Walaupun di antara para ahli ada perdebatan tentang berapa jumlah kata yang tepat dalam penggunaan ruakh sebagai "angin" dalam PL, namun mayoritas setuju bahwa kata itu muncul antara 113 dan 117 kali. Perlu disadari bahwa kadang-kadang perbedaan yang terjadi sangat tergantung pada konteksnya, misalnya apakah penggunaan kata dalam ayat-ayat itu bermakna sebagai kiasan, literal, atau metaphora. ${ }^{29}$ Maka dalam berbagai konteks, seperti dunia kosmologi dan meteorologi maka dengan mudah untuk menerjemahkan kata ruakh sebagai "angin."

Beberapa data dalam PL yang menggunakan kata ruakh sebagai "angin" juga digunakan menjadi alat di tangan Tuhan untuk mencapai tujuan ilahiNya. Dalam peristiwa air bah, ruakh diutus Allah untuk menghalau banjir dari atas bumi (Kej 8: 1). Senada dengan itu, informasi yang diberikan kitab Keluaran tentang perseteruan antara Tuhan Allah dengan Firaun, maka angin digunakan sebagai kekuatan untuk mendatangkan malapetaka dan juga menghalau mala-petaka itu.

Juga digambarkan bahwa Allah bekerja melalui angin timur untuk membawa wabah belalang atas tanah Mesir yang

${ }^{29}$ H. W Wolff, Anthropology of the Old Testament (trans. M. Kohl; Philadelphia: Fortress, 1974) 32; H. W Robinson, Inspiration and Revelation in the Old Testament (Oxford: Clarendon, 1946) 74 memakan habis segala tumbuhan (Kel 10:13). ${ }^{30}$ Namun setelah berbagai dialog antara Musa dengan Firaun, maka dengan memohon pertolongan Tuhan angin barat diutus menghalau tulah belalang itu (Kel 10:19). TUHAN meng-gunakan ruakh sebagai kuasa untuk menyebabkan angin diperintahkan mem-bawa buruh puyuh sekaligus pula angin yang membawa malapetakan keluar (Bil 11:31). TUHAN menggunakan angin sebagai alat untuk menyelamatkan umatNya (Kel 14:21), dan sekaligus pula sebagai kuasa yang menghukum atau menghancurkan para musuhNya (Bil 11:31).

Pengalaman Israel menyaksikan kuasa Tuhan yang dasyat melalui angin juga diperlihatkanNya pada peristiwa Israel menyeberang Laut Merah. Meng-hadapi kedasyatan laut itu, Allah mengirim angin timur yang sangat kuat sehingga mampu membelah laut itu dan dengan jalan itu umat Allah dapat menye-beranginya (Kel 14:21). Angin juga dipakai Allah sebagai alat untuk menjaga kesinambungan hidup umat di padang gurun. Pemeliharaan Allah di padang gurun itu dinyatakan dengan kehadiran angin barat yang membawa burung puyuh (Bil 11:31).

Ruakh dalam kitab para nabi (Nevi'im). Kitab Yesaya dan Yehezkiel misalnya, lebih banyak menggunakan kata ruakh itu jika dibandingkan dengan kitab nabi besar lainnya. Kitab Yeremia sendiri memakai kata "roh" sebanyak 18 kali dalam kaitannya dengan "angin" yang memperlihatkannya sebagai alat dalam tangan Tuhan untuk mencapai tujuanNya. Secara metaforis banyak naskah PL yang memperlihatkan angin timur sebagai pembawa malapetaka, sementara angin barat sebagai pembawa kelepasan dan pembebasan. Misalnya tampak dalam pemberitaan nabi Yeremia, "Seperti angin timur Aku akan menyerakkan mereka di

30 J Vernon McGee, Thru The Bible: Genesis Through Deuteronomy, (Nashville: Thomas Nelson Publishers, 1981), 232-233 
depan musuhnya. Belakang-Ku akan Kuperlihatkan kepada mereka dan bukan muka-Ku pada hari bencana mereka" (Yer 18:17; Yeh 17:10; 19:12).

Para nabi seringkali menggunakan pemahaman umum dari angin sebagai "kuasa yang menghancurkan," "sangat kuat," "menggertak," dan "per-kasa." Seringkali, angin dikaitkan dengan kuasa yang menghancurkan yang membawa hujan lebat, hujan es, atau langit gelap gulita (1 Raj 18:45; 19:11; lih 2 Raj 3:17). Angin juga dapat digunakan dalam arti kiasan seperti dalam Yesaya 7: 2, di mana hati yang terguncang digambarkan dengan pohon yang ditiup oleh angin, atau dalam penilaian hidup yang sia-sia yang digambarkan seperti sekam ditiup angin (Yes. $17: 13){ }^{31}$

Secara metaforis "angin" menjadi ekspresi penghukuman Allah. Yeremia memperlihatkan angin yang datang dari "empat penjuru langit" sebagai simbol penghakiman Allah yang dijatuhkan atas Elam (Yer 49:36). Dengan cara interpretasi yang berbeda nabi Yehezkiel juga menggunakan istilah "empat penjuru angin" untuk menunjuk kiasan untuk asal-usul "nafas" yang akan menghidupkan "tulangtulang" yang berserakan dan memberi mereka kehidupan, ... "Ber-nubuatlah kepada nafas hidup itu, ber-nubuatlah, hai anak manusia, dan katakan-lah kepada nafas hidup itu: Beginilah firman Tuhan ALLAH: Hai nafas hidup, datanglah dari keempat penjuru angin, dan berembuslah ke dalam orang-orang yang terbunuh ini, supaya mereka hidup kembali..." (Yeh 37: 9-10). ${ }^{32}$ Dalam teks ini, istilah ruakh digunakan lima kali dan diterjemahkan terutama dalam pengertian antropologi yaitu nafas-kehidupan.

Kendali Tuhan atas angin dicatat secara metaforis sebagai angin yang

${ }^{31}$ H.C. Leupold, Exposition of Isaiah, Chap 1-29. Vol. I (Grand Rapids: Michigan: Book House, 1991), 299

32 J Vernon McGee, Thru The Bible: Proverbs Through Malachi, Vol. III, (Nashville: Thomas Nelson Publishers, 1982), 509-510 dibawa keluar dari "perbendaharaan Allah, Apabila Ia memperdengarkan suaraNya, menderulah bunyi air di langit, Ia menaikkan kabut awan dari ujung bumi, Ia membuat kilat serta dengan hujan, dan mengeluarkan angin dari perbendaharaan-Nya (Yer 10:13). Dalam cacatan lain diperlihatkan bahwa asal-usul "setiap angin" adalah dari Allah sendiri (Yer 49:32; Yeh 5: 10,12; 14; 17:21). ${ }^{33}$ Nabi Amos menyatakan dengan tegas bahwa Allah adalah pencipta angin (Amos 4:13). Adalah hal umum bagi para nabi bahwa penggunaan angin sebagai alat untuk menyatakan kuasa dan otoritas Allah. Secara simbolik ada kalanya "angin" digunakan sebagai tanda per-lindungan bagi perjanjian Allah, namun di sisi lain angin digunakan untuk peng-hakiman akibat pelanggaran terhadap perjanjian. ${ }^{34}$

Nabi Hosea dalam nubuatnya menggunakan istilah "angin" sebagai perealisasian hukuman atau penghakiman. ${ }^{35}$ Banyak fakta dimana para nabi menggunakan angin sebagai alat penghakiman yang akan datang dari Allah, dengan cara mengarahkan angin untuk tujuan hukuman. Kritik nabi Hosea atas pelanggaran perjanjian yang dilakukan Israel dengan cara penyembahan berhala. Ketidaktaatan yang dilakukan melalui penyembahan berhala itu disebut sebagai orang yang "menabur angin" (Hos 8: 7). ${ }^{36}$

Terkait dengan itu, tindakan Israel yang melakukan praktik peribadatan kafir dan penyembahan berhala sudah pasti akan menuai penghakiman yang dilambangkan dengan datangnya angin timur yang panas. Nyatanya penghakiman dari timur itu jelas digenapi dengan hadirnya invasi dari tentara Asyur (Hos 13:15; bnd. 12: 1). ${ }^{37}$ Memang penyebutan angin timur oleh para nabi lebih dominan digunakan untuk tujuan penghakiman itu (Yer 18:17; Yeh 17:10;

\footnotetext{
${ }^{33}$ Barth, God With Us, 317-318

${ }^{34}$ Barth, God With Us, 320 - 321

${ }^{35}$ Barth, God With Us, 321 - 324

${ }^{36}$ Barth, God With Us, 307

${ }^{37} \mathrm{~J}$ Vernon McGee, Thru The Bible, 654
} 
19:12; Yunus 1: 4; 4: 8). Proklamasi penghakiman melalui angin timur dikaitkan dengan sifatnya yang bertiup dengan kencang dan panas, sehingga dengan mudah melayukan tanaman dan menjadi siksaan bagi mahluk hidup. Allah melepaskan angin keras sebagai penyataan murkaNya (Yeh 13:11). ${ }^{38}$

Sementara itu, penyembahan berhala diumpamakan seperti hembusan nafas yang akan hilang dalam sekejap (Yes 57:13). Penyembahan berhala digambarkan dengan tindakan mengambil orang-orang seperti sekam yang ditiup angin di tempat pengirikan (Yer 4: 11-12; lih Yes 41:16). Hasil akhir dari penyembahan berhala adalah kesia-siaan yang akan hilang tanpa bekas (Yer 41:29). Para penjaga dan gembala Israel yang membawa umat itu masuk ke dalam penyembahan berhala juga akan hilang ditiup angin (Yer 22:22). Para nabi palsu yang memberitakan kebohongan dan menjauhkan umat dari kebenaran firman dan wahyu Allah juga akan hilang seperti ditiup angin (Yer 5:13; Mik. 2:11).

Di hadapan Allah, manusia hanyalah seperti rumput dan akan layu (Yes 40: 7). Hidup manusia berdosa sama seperti menyapu angin di atas bumi, "demikianlah kami sekalian seperti seorang najis dan segala kesalehan kami seperti kain kotor; kami sekalian menjadi layu seperti daun dan kami lenyap oleh kejahatan kami seperti daun dilenyapkan oleh angin (Yes. 64: 6). ${ }^{39}$ Penggunaan "angin" tidak selama-nya ditampilkan sebagai kehadiran penghukuman Allah atas dosa umatNya. Rupanya "angin" juga dipakai Tuhan menjadi kendaraanNya, "Ia mengendarai kerub, lalu terbang dan melayang di atas sayap angin" (Mzm 18:10; 104: 4; 148: 8).

\section{Ruakh dalam Kitab-kitab (Ketu-} vim).

Dalam sastra Hikmat, "angin" sering digunakan untuk membandingkan sifat angin yang berlalu dengan cepat sebagai gambaran yang memperlihatkan kekosongan dan kesia-siaan hidup. Ungkapan "mengejar angin" yang dipahami sebagai sebuah kebodohan (Pkh 1: 14,17; 2: $11,17,26 ; 4: 4,6,16 ; 6: 9)$. Secara metaforis angin digunakan dalam aspek ilusi yakni kehidupan seperti warisan kosong. Hal itu dideskripsikan dengan orang yang sudah kerja keras namun tanpa imbalan (Ams. 11:29; 25: 4; 27:16; Pkh 5:16). ${ }^{40}$

Penyampaikan kata-kata yang tidak bermakna, seperti kata-kata pidato tanpa kebijaksanaan, atau ucapan tanpa isi disebut sebagai "angin yang berlalu" (Ayub 6:26; 8: $2 ; 16: 3)$. Di saat peng-hakiman, angin ditampilkan dalam sifatnya destruktif karena membawa mala-petaka, kehancuran, kekeringan, dll. Peng-gambaran metaforis "angin" diperlihatkan untuk menunjukkan sifat kesia-siaan, ke-hampaan dan berlalu dengan cepat, seperti tampak dalam penggunnaan angin untuk menerbangkan sekam, menyapu debu, goyang pohon, dan layu tanaman.

Dalam sastra Hikmat, penggunaan istilah "roh" sebagai "angin" ditampilkan dalam banyak konteks terutama yang memperlihatkannya sebagai alat Tuhan. Seperti umum diketahui bahwa Allah sendirilah yang menciptakan angin untuk tujuanNya. Allah dapat menggunakan angin dari perbendaharaan hikmatNya. Allah mengirim angin sesuai dengan musimmusim untuk membawa awan bagi hujan, badai dan sebagai fenomena alam yang normal dalam siklusnya. Angin adalah instrumen dan utusan di tangan Tuhan melaluinya tujuan ilahi dapat tercapai. Faktanya, angin memang tak terlihat, sulit dipahami yang mem-perlihatkan keadaan hidup dalam berbagai dimensi dan kondisi yang ada.

\section{Ruakh dalam Hubungannya dengan Manusia}

Pada konteks penggunaan ruakh pada manusia, maka jelas bahwa istilah itu

${ }^{40}$ J Vernon McGee, Thru The Bible, 42-43
${ }^{38}$ Barth, God With Us, 332-333

${ }^{39}$ Barth, God With Us, 324-326 
adalah antropologi dan psikologi. Oleh karena istilah itu digunakan dalam banyak kasus sehingga pengertian dan maknanya pun menjadi beragam. Ada kalanya kata itu dengan mudah dipahami jika peng-gunaan kata yang disampaikan dalam bentuk informasi. Namun berbeda halnya jika penggunaan kata itu ditampilkan dengan konotasi yang berbeda atau bahasa kiasan.

Bila nafas dikaitkan dalam bentuk fisik maka secara sederhana ungkapan itu ditujukan kepada mahluk hidup sudah tentu akan sangat mudah dipahami maksudnya. Namun jika ungkapan nafas atau angin digunakan secara figuratif misalnya yang hendak menunjuk pada keadaan psikologis dan emosi seseorang maka kita perlu pemahaman yang lebih dalam. Pada kenyatannya, berbagai istilah al-kitabiah yang menggunakan kata ruakh disajikan untuk memperlihatkan sifat antropologis dan eksistensi manusia dalam cakupan pengertian yang luas. Dengan demikian diperlukan sikap kehati-hatian untuk mempertimbangkan konteks tertentu dimana kata itu digunakan agar makna dan signifikansinya menjadi tepat.

Menurut R. G. Bratcher, ${ }^{41}$ dalam perspektif PL kata ruakh ditempatkan dalam konteks antropologi. Ia menganggap bahwa para penulis Alkitab melihat manusia sebagai satu dan keseluruhan, unit yang tidak dapat dibagi menjadi bagianbagian yang terpisah, masing-masing dengan keberadaan terpisah sendiri. Artinya, manusia tidak hanya dipandang sebagai manusia yang sekedar me-miliki fisik (daging, tubuh) saja, namun juga secara spiritual (roh, jiwa), dan (pikiran, hati) bagian intelektual dan emosional.

Sekalipun masing-masing bagian dapat dijelaskan secara terpisah namun bukanlah setiap bagian menunjuk kepada manusia yang berbeda sama sekali. Dalam konteks tertentu manusia dipandang sebagai seseorang yang memiliki ke-

${ }^{41}$ Wilf, An Old Testament Theology of the Spirit of God, 12 hendak, kecerdasan, naluri, keinginan, gairah, emosi dan yang lainnya. Namun manusia juga dapat digambarkan hanya dengan satu bagian saja dari anggota tubuh tetapi mewakili keseluruhannya, misalnya hati, mata, kepala, roh, jiwa, dll.

Untuk itu kita perlu pembangunan konsep berfikir dalam mengamati berbagai penggunaan kata ruakh dalam kaitannya dengan manusia. Misalnya, Nabi Maleakhi menggunakan ungkapan "yang tidak setia terhadap isteri dari masa mudanya" (Mal. 2: 15-16; lih Yes 54: 6). Penggunaan isteri pada masa muda bukanlah dimaksudkan sebagai sepasang suami isteri, melainkan gambaran terhadap ketidaksetiaan seluruh umat Israel sebagai suatu bangsa kepada Tuhan.

Para nabi dilengkapi dengan roh Tuhan untuk menyampaikan pesan sesuai konteks sejarah saat itu. ${ }^{42}$ Dalam pengharapan masa depan umat Allah, karya ruakh dihubungkan dengan berita keselamatan yang akan diperoleh umat itu yakni sisanya. Ungkapan Tuhan akan memberi roh ruakh keadilan bagi orang yang duduk mengadili, dan menjadi roh ruakh kepahlawanan bagi orang yang memukul mundur peperangan ke arah pintu gerbang" (Yes 28: 6). ${ }^{43}$

Karya Roh Allah pada zaman nabi Elia selalu menjadi landasan kuat bagi kita untuk memahami bagaimana roh Allah bekerja bagi nabi-nabi di kemudian hari. Dalam tradisi kenabian, narasi per-pisahan antara Elia dan Elisa menjadi penegasan betapa pentingnya roh Allah bagi pelayanan nabi. Sebab dengan jelas dikemukakan bahwa Elisa meminta "rohnya dua bagian" (2 Raj 2: 9). Per-mintaan ini dikabulkan Elia, dengan cara demikian maka para nabi lainnya meng-akui keberadaan roh pada Elisa (2 Raj 2:15).

Sebaliknya para nabi palsu juga menggunakan ruakh dalam pengertian yang negatif, untuk bernubuat dengan ber-

${ }^{42}$ Gerhard von Rad, Theology of The Old Testament, OTL. Philadelphia. 1990

${ }^{43}$ H.C. Leupold, Exposition of Isaiah, 437 
bagai cara. Umumnya nabi palsu mengklaim dirinya sebagai nabi tanpa pengakuan dari komunitas. Para nabi itu bernubuat sesuai keinginan diri sendiri atau pesanan yang diminta pihak tertentu, namun bukan atas keinginan dan wahyu dari Tuhan (Yeh 13: 3; lih 13: 7). Nubuat nabi palsu adalah sebuah kebohongan yang berasal dari "roh" tidak murni (Zak 13: 2).

Dengan demikian nubuat mereka tidak akan membawa pembaharuan bagi umat Allah, sebaliknya mereka "tidur nyenyak" secara rohani (Yes 29:10). Roh Allah diberikan kepada para nabi untuk memberi pengertian, "orang-orang yang sesat pikiran akan mendapat pengertian, dan orang-orang yang bersungut-sungut akan menerima pengajaran" (Yes 29:24). ${ }^{44}$ Secara emosi manusia mudah untuk berubah baik yang positif maupun yang negatif. Allah berkenan kepada orang yang rendah hati dan mau menyesal (Yes 66: 2; 57: 15-16).

Tuhan memanggil umatNya untuk meninggalkan kejahatan dan dosa mereka untuk berbalik dari dosa dengan roh dan hati yang baru (Yeh 18:31; Yes 65:14). Respon Allah terhadap pertobatan umatNya adalah mereka akan memperoleh "hati yang baru" dan "roh yang baru", "Aku akan memberikan mereka hati yang lain dan roh yang baru di dalam batin mereka; juga Aku akan menjauhkan dari tubuh mereka hati yang keras dan memberikan mereka hati yang taat..." (Yeh 11:19; 36:26).

\section{Ruakh sebagai Roh Allah}

Bagian ini adalah gambaran yang memperlihatkan dokumen dan teks-teks kunci yang memperlihatkan ruakh secara khusus yang merujuk kepada Roh Allah dan bagaimana Ia melakukan karya-Nya dalam PL. Dari analisis yang menyeluruh ter-hadap PL, maka empat kategori tematik terhadap ruakh yang menunjuk kepada Allah sendiri. Pertama, roh Allah yang aktif berkarya dalam penciptaan. Dalam PL, istilah ruakh dihubungkan langsung dengan
Allah digunakan sekitar seratus tujuh kali. Sementara penggunaan frase ruakh elohim "Roh Allah" kurang lebih lima belas kali; sedangkan frasa -ruakh YHWH "Roh Tuhan" sekitar dua puluh tujuh kali. Roh Allah dipandang sebagai kuasa yang aktif bekerja dan berkarya dalam alam semesta. Karya Roh Allah tampak dalam peristiwa penciptaan manu-sia dalam penciptaan dan alam semesta.

Kedua, roh Allah yang membebaskan dan memerdekakan. Melalui karya roh Allah yang aktif maka Israel telah menikmati pengalaman tentang pembebasan, keselamatan, bimbingan, dan kehadiran Allah. Ketiga, roh Allah memilih para pemimpin bagi umatnya. Mereka juga yakin bahwa Roh Allah berkenan menuntun dan membimbing para pe-mimpin di tengah-tengah umat Allah. Keempat, roh Allah menuntun para nabi. Hal itu tampak jelas dalam pelayanan para nabi dalam seluruh pemberitaannya dan bagaimana mereka dilengkapi dalam pe-laksanaan tugas kepemimpinan lainnya.

\section{DAFTAR PUSTAKA}

Blenkinsopp, J., A History of Prophecy in Israel, Louisville (Westminster: John Knox), 1996

Baker David. L, John J. Bimson, Mari Mengenal Arkeologi Alkitab, (Jakarta: BPK GM), 2004

Barth Christoph, God With Us, A Theological Introduction to The Old Testament, (Grand Rapids: Michigan, William B Eerdmans, 1991

Barth, C., Theologia Perjanjian Lama 4, Jakarta (BPK-GM) 1993

Blocher H.A.G, "Evil", in New Dictionary of Biblical Theology, Exploring the Unity and Diversity of Scripture., T Desmond Alexander, (ed.), (Downers Grove, Illinois: Intervarsity Press, 2001), 465-467 
Blocher H.A.G, "Everlasting punishment and the problem of evil", in Universalism and The Doctrine of Hell, N.M de S. Cameron, (ed.), (Carlisle and Grand Rapids, 1992), 281-312

Bullock C. Hassel, Kitab Nabi-nabi Perjanjian Lama, (Malang: Gandum Mas), 2002

Champbell Don, Wendell Johnston, John Walvoord, John Witmer, The Theological Wordbook: The 200 Most Important Theological Terms and Relevance for Today, Ed. Charles Swindoll, Roy B Zuck (Nashville: Word Publishing), 328329

Chisholm Robert B, "Teologi Kitab-kitab Nabi Kecil", dalam Teologi Alkitabiah Perjanjian Lama, terj. Suhadi Yeremia, Biblical Theology of The Old Testament. Malang: Gandum Mas, 2005.

Cody A., A History of Old Testament Priesthood, Rome (Pontifical) 1969

Clay, Martin, "The Book of Twelve", in A Biblical Theology of The Holy Spirit, (Ed.) Trevor J Burke and Keith Warringon, Great Britain: SPCK, 2014.

Davidson F (ed.), The New Bible Commentary, (London: The Inter Varsity Fellowship) 1962

Delitzsch F,CF Keil, Commentary on The Old Testament, Job (Peabody, Masschusetts: Hendrickson) 1989

Delitzsch F,CF Keil, Commentary on the Old Testament: Joshua, Judges, Ruth, (Peabody, Massaschusetts: Hendrickson Publishers), 1989

Dunn JDG, "Spirit, Holy Spirit", The Illustrated Bible Dictionary, Part 3, P-Z, Ed. Mary Gladstone, etc. (Leicester:Inter-Varsity Press, 1980), 1478-1483

Enns Paul, The Moody Handbook of Theology, (Malang: SAAT, 2004), 301-306

Firth, David., "The Historical Books" in $A$ Biblical Theology of The Holy
Spirit, Treveor J Burke, Keith Warrington ed., (London: SCPK, 2014), 18-19

Fong Yap Wei (terj.), Hand Book to The Bible (Bandung: Kalam Hidup, 2004), 269.

Gilbert P.J, "Spiritual Warfare" in William Dyrness , Veli Matti Karkainen (Ed.), Global Dictionary of Theology, (Illinois Notingham: Intervarsity Press, 2008), 847-851

Heaton, E.., The Old Testament Prophets, London (Darton, Longman \& Todd), 1985

Hildebrandt, Wilf, An Old Testament Theology of the Spirit of God (Peabody, Massachusetts: Hendrickson Publishers), 1995

Hill Andrew E., John H Walton, Survey Perjanjian Lama, Malang: Gandum Mas, 1996

Kleinknecht H., "pneuma, pneumatics' TDNT

Mays, J, L \& Achtemeir, P, J., Interpreting The Prophets, (Philadelphia Fortress), 1985

McGee J Vernon, Thru The Bible: Genesis Through Deuteronomy, Vol. I (Nashville: Thomas Nelson Publishers), 1981

McGee J Vernon, Thru The Bible: Proverbs Through Malachi, Vol. III, (Nashville: Thomas Nelson Publishers), 1982

Motyer, J,A., 'Nubuat Nabi-nabi', Ensiklopedi Alkitab Masa Kini, Jilid II, M-Z, Jakarta (YKBK), 1996

Leupold H.C., Exposition of Isaiah, Chap 1-29. Vol. I (Grand Rapids: Michigan: Book House), 1991)

Johnson A. R., The Vitality of the Individual in the Thought of Ancient Israel (2d ed.; Cardiff: University of Wales Press, 1964)

Kraus, J.,Umat Allah Dalam Perjanjian Lama, Jakarta: BPK Gunung Mulia, 1993

Obrempong J Nkansah, "The Problem of Evil", in Global Dictionary of Theology, William Dyrness, Veli 
Matti Karkainen (Ed.), (Illinois Notingham: Intervarsity Press, 2008), 300-303

Rehm, D. "Levites and Priests" The Anchor Bible Dictionary, vol 4, K-N, (New York: Doubleday, 1922)

Richards, Lawrence O., Expository Dictionary of Bible Words, (Grand Rapids-Michigan: RegencyZondervan), 1985

Robinson H. W, Inspiration and Revelation in the Old Testament (Oxford: Clarendon), 1946

Schoemaker W.R, "The Use of ruah in the Old Testament and of pneuma in the New Testament," JBL 23 (1904)

Tounge, D.A "Imam dan Orang Lewi" Ensiklopedi Alkitab Masa Kini, (Jakarta: YKBK, 1994)

Tuner M, "Spiritual Gifts" in New Dictionary of Biblical Theology, Exploring the Unity and Diversity of Scripture., Ed. T Desmond Alexander, et.all., (Downers Grove, Illinois: Intervarsity Press, 2001), 789- 796

Unger Merrill F., Nelson's Dictionary of The Old Testament, (Nashville: Thomas Nelson Publish.), 1980

Von Rad, G., The Old Testament Prophets, New York (Harper and Row), 1965

Van Gemeren Willem., Penginterpretasian Kitab Para Nabi (Surabaya: Momentum), 2007

Wilson, R, R Prophecy and Society in Ancient Israel, Philadelphia (Fortress), 1980

Waltke K Bruce., An Old Testament Theology: an Exegetical, Canonical, and Thematic Approach, (Grand Rapids, Michigan, Zondervan) 2006

Wolff H. W, Anthropology of the Old Testament (trans. M. Kohl; Philadelphia: Fortress) 1974

Young Edward J., The Book of Isaiah. Vol. 1 (Grand Rapids, Michigan), 1965

Zuck Roy B. (ed), A Biblical Theology of The Old Testament, Terj, Suhadi Yeremia, Teologi Alkitabiah
Perjanjian Lama (Malang: Gandum Mas) 2005

BibleWorks 9

E-sword, The Sword of Lord with an electronic edge 


\section{BIODATA PENULIS}

Gernaida K.R. Pakpahan menyelesaikan pendidikan Sarjana Teologi di ITKI (Institut Teologi dan Keguruan Indonesia), Jakarta; Magister Artium in Church Ministries di ITKI (Institut Teologi dan Keguruan Indonesia), Jakarta; Magister Divinity di ITKI (Institut Teologi dan Keguruan Indonesia), Jakarta; Magister Teologi di STT (Sekolah Tinggi Teologi), Jakarta; Doctor of Ministry di STII (Sekolah Tinggi Injili Indonesia), Yogyakarta; Doctor Teologi di STBI (Sekolah Tinggi Baptis Indonesia), Semarang. Beliau adalah dosen tetap di STT Bethel Indonesia (dahulu ITKI) sejak 1994 dan dosen tidak tetap dibeberapa Perguruan Tinggi Teologi. Pernah menjabat sebagai direktur program pasca-sarjana STT Bethel Indonesia (20042008), pernah menjabat sebagai Ketua STT Bethel Indonesia (2008-2016). Selain itu, penulis juga aktif di organisasi antara lain sebagai bendahara PERSETIA (1997-2004), Ketua Departemen Teologi BPH GBI (2004-2008), dan anggota Komisi Kajian Biblika LAI. Saat ini penulis masih menjabat sebagai Ketua Program Studi Doctor Teologi di STT Bethel Indonesia 